\title{
ALTES UND NEUES ÜBER DIE STIGMATISATION DES HL. FRANZ VON ASSISI VON KARL HAMPE
}

Im 96. Bande der Historischen Zeitschrift habe ich vor einigen Jahren in einem kurzen Aufsatze die eigenartigen Probleme neu zu behandeln versucht, welche der psychologisch und̀ religionsgeschichtlich höchst bemerkenswerte Vorgang der Stigmatisation des hl. Franz von Assisi darbietet. Ohne hier jene Darlegungen, die ich als bekannt voraussetzen muß, im einzelnen wiederholen zu wollen, möchte ich nur die Hauptergebnisse andeuten. Ich suchte einmal gegen Karl v. Hase zu erweisen, daß Franzens Wundmale nicht das Werk frommen Betruges an seiner Leiche, vollbracht durch den ehrgeizigen Ordensgeneral Elias, sein konnten, weil sich außer Elias noch andere Augenzeugen nennen lassen, welche die Wundmale schon an dem Lebenden beobachteten, und weil die Annahme, auch sie seien mit im Komplott gewesen, um die Welt, wenn auch in frommer Absicht, so doch bewußt, zu hintergehen, zu starken Unwahrscheinlichkeiten fủhren würde. Was das Aussehen der Wundmale an Händen und Füßen betrifft, so glaubte ich entgegen der Ansicht aller neueren Darsteller aus dem unmittelbar nach dem Tode des Heiligen geschriebenen Briefe des Elias entnehmen $z u$ sollen, daß es dunkelfarbige, vernarbte Wundlocher waren, nicht aber nägelartige, außen und innen wie Köpfe und Spitzen von Nägeln hervortretende schwärzliche Fleischgebilde. Den Zeitpunkt, an dem die Stigmatisation erfolgte, meinte ich, entgegen der allgemeinen und durch die Autorität der Kirche gestützten Anschauung, auf Grund einer richtigen Bewertung der voneinander abweichenden Quellenangaben ganz dicht an Franzens Tod heranrucken zu müssen. Der Vorgang hat, so führte ich aus, 
ursprünglich mit der Seraphsvision, die dem Heiligen im September 1224 in der Bergeinsamkeit des Monte Alverno zuteil wurde, nichts zu tun. Erst als nach seinem Tode die Bruder, die über Zeit und Art der Entstehung nichts Genaues wußten und ein làngeres Verborgenhalten durch den demütigen Heiligen für moglich hielten, fur die Darstellung seines Lebens nach einem bestimmten, eindrucksvollen Moment suchten, der für das Auftreten des Gnadenwunders eine gewisse innere Wahrscheinlichkeit bot, verfielen sie auf die Fastenzeit des Monte Alverno, das Kreuzerhöhungsfest und die damalige Seraphsvision ihres Stifters. Diese Vermutung wurde bald zur Gewißheit und fand nach der auch ästhetisch eindrucksvollen legendarischen Ausgestaltung des Thomas von Celano kanonische Geltung. - Nur mit wenigen Worten deutete ich zum Schlusse an, welche naturlichen Erklärungsmöglichkeiten sich etwa für die seltsame Erscheinung der Stigmatisation darbieten, ohne daß ich es für meine Aufgabe als Historiker gehalten hätte, da eine bestimmte Entscheidung zu treffen.

Mit der Aufnahme, welche diese meine Aufstellungen seither von der Forschung erfahren haben, kann ich wohl zufrieden sein. Ausführlichere Äußerungen liegen von zwei Seiten vor. Einmal von kirchlich-franziskanischer: P. Michael Bihl O. F. M. hat in der Abhandlung: "Die Stigmata des hl. Franz von Assisi“ im Historischen Jahrbuch der Goerresgesellschaft Bd. 28 (1907) S. $529 \mathrm{ff}$. dem gegen Hase gerichteten Teil meiner Ausführungen Beifall geschenkt, meine ubrigen Ergebnisse, soweit sie mit der herrschenden kirchlichen Auffassung in Widerspruch stehen, abgelehnt. Ich habe das durchaus nicht anders erwartet, und da die Polemik in hoflicher Form und nicht ohne Geschick gefuhrt ist, so daß es sich immerhin lohnt, mit dem Gegner die Klinge zu kreuzen, so war von dieser Seite her sicherlich nicht mehr zu verlangen.

Neuerdings hat Josef Merkt, ein Schuler von W. Goetz ${ }^{1}$ ) in Tubingen, die Stigmatisationsfrage einer umfassenden Unter-

1) Dieser selbst in seinem Büchlein „Assisi" 1909 (Berühmte Kunststätten Bd. 44) behandelt S. 53-56 die Frage kurz in mehr konservativem Sinne, immerhin nicht ganz ohne Beeinflussung durch meine Abhandlung. Auf einzelne seiner Urteile komme ich unten zurück. 
Altes und Neues uber die Stigmatisation des hl. Franz von Assisi 259

suchung unterworfen und seine Ergebnisse niedergelegt in dem Buchlein: „Die Wundmale des heiligen Franziskus von Assisi" (Beiträge zur Kulturgeschichte des Mittelalters und der Renaissance Heft 5) 1910.1) Obwohl bei weitem nicht alles, was da vorgebracht wird, kritisch haltbar ist, wird man die Schrift doch als eine nützliche und anregende Forderung der Frage bezeichnen durfen. Soweit aber neues Material von Bedeutung beigebracht ist, trägt es wesentlich zur Stutze meiner Aufstellungen bei.

Indem ich es im folgenden unternehme, mich mit diesen beiden Abhandlungen auseinanderzusetzen, glaube ich die Sache, um die es mir allein zu tun ist, am besten fördern zu können. Persönlich würde es mir bei einer Forschung, die sich auf so schwierigem und unsicherem Boden bewegt, und deren Ergebnisse bis zu einem gewissen Grade wohl stets einen hypothetischen Charakter bewahren werden, wirklich nicht schwerfallen, einzuräumen, daß meine Aufstellungen in diesem oder jenem Punkte nicht überzeugend oder gar unhaltbar seien. Aber ich sehe dazu bei ernstlicher Prufung doch keine Veranlassung. -

Übereinstimmung herrscht daruber, daß die Wundmale schon zu Lebzeiten Franzens von Augenzeugen beobachtet sind, denen unser Vertrauen nicht ohne weiteres versagt werden darf. Mit Merkt rechne ich Gregor IX. nicht unter diese Zahl, wenn ich auch schärfer als er betonen möchte, daß der von Bonaventura berichtete $Z$ weifel Gregors doch nur der nicht sichtbaren Seitenwunde, nicht den Stigmen überhaupt galt. Für Papst Alexan der IV. aber bestreitet Merkt (S. I4ff.) die von mir (und Bihl) angenommene Augenzeugenschaft und geht auf die Ansicht Hases zurück. Indessen scheint er mir hier in seiner Beweisführung nicht eben glücklich zu sein. Nach Lage der Dinge möchte ich auf eine Augenzeugenschaft Alexanders nicht gerade schwören, halte sie aber immerhin für wahrscheinlich. Die Annahme ruht auf der Aussage Bonaventuras (Leg, mai. XIII, 8): „Summus etiam pontifex dominus Alexander, cum populo praedicaret, coram multis fratribus et me ipso affirmavit se, dum Sanctus viveret, stigmata illa sacra suis oculis conspexisse. " $\mathrm{Da}$ die Wahr-

1) Vgl, diese Zeitschrift oben S. $222 \mathrm{f}$. 
heitsliebe Bonaventuras nicht wohl bezweifelt werden kann, muß Merkt mit Hase zu dem Ausweg greifen, jener habe „in seinem Übereifer, überall Augenzeugen der Stigmen aufzuspüren," eine "durch die Berufung auf die im Dienste seines Oheims (Gregors IX.) gewonnene Bekanntschaft mit dem Heiligen eindringlicher gemachte Behauptung Alexanders IV. über die Stigmen Franzens mißdeutet oder falsch verstanden". Angesichts der unzweideutigen Äußerung Bonaventuras ist das doch mehr ein Notausweg, den man allenfalls einschlagen müßte, wenn der behaupteten Tatsache sichere Belege entgegenständen. Das ist indes nicht der Fall. Was ihr angeblich widerspricht, ist nur der Umstand, daß Alexander IV. in einer Bulle vom 29. Oktober I255 (Potth. 16077 ), in der er aufgetauchte Zweifel an Franzens Stigmatisation bekämpft, statt der nackten Versicherung „, Ich selbst habe die Wundmale gesehen," sich einer Umschreibung von unbestimmterer Allgemeinheit bedient. Merkt verschiebt hier einigermaßen die Sachlage, wenn er mich und andere Forscher eben in dieser Bulle einen unzweideutigen Beleg für die Augenzeugenschaft finden, ja wenn er mich aus ihr ein "nacktes": "Ich selbst habe die Wundmale gesehen" herauslesen läßt. Das ist nirgends geschehen! Der eigentliche Beleg bleibt natürlich die Äußerung Bonaventuras; es fragt sich nur, ob die allgemeinere Fassung der Bulle, in der nach meinen Worten gerade ein nacktes: "Ich selbst habe die Wundmale gesehen" fehlt, zu Bonaventura in derartigem Widerspruche steht, daß wir bei diesem notwendig ein Mißverständnis anzunehmen haben.

Ich muß die betreffende Stelle der Bulle hierher setzen. Nach der Versicherung der Tatsächlichkeit der Stigmen fährt sie fort: "Sane de praefato Sancto haec certius asserentes, indoctas fabulas seu vanae inventionis deliramenta non sequimur, cum ea nobis dudum nota fecerit plenior fides rerum, quando videlicet in minoribus constituti, confessoris eiusdem familiarem ex munere divino meruimus habere notitiam, praefati praedecessoris nostri domesticis obsequiis tunc temporis insistendo." Merkt legt (immer im Anschluß an Hase) Gewicht darauf, daß hier eine offenkundige Anlehnung an die Kanonisationsbulle Gregors IX. von 1228 vorliege, nämlich an die Stelle: „Cum igitur gloriosae vitae ipsius 
Altes und Neues über die Stigmatisation des hl. Franz von Assisi 26 I

insignia ex multa familiaritate, quam nobiscum habuit in minori officio constitutis, plene cognita nobis essent, et de miraculorum coruscatione multiplici per testes idoneos facta fuerit plena fides, - ipsum adscribi decrevimus sanctorum catalogo venerandum", und er fährt fort: "das 'plena fides' hat also hier die Bedeutung: 'ein durch Zeugen vermittelter Glaube'; dieselbe Bedeutung muß aber bei der sprachlichen Anlehnung der beiden Schriftstucke auch das 'plenior fides' in der Bulle Alexanders IV. haben, und zwar dies um so mehr, als Alexander in seinem Briefe an die Bischöfe von Kastilien von I259 (Wadding, Ann. Min. ed. 2. IV, I05ff.) seine Verteidigung der Wundmale Franzens auch nicht durch den Hinweis auf seine Augenzeugenschaft, sondern ebenfalls durch die Berufung auf die Berichte 'quorundam fide dignorum' führt."

Trotz der ziemlich stereotypen Phrasen, in denen sich die Übereinstimmung zeigt, möchte ich nicht bezweifeln, daß dem Verfasser der Bulle Alexanders IV. eine Erinnerung an Gregors IX. Kanonisationsbulle vorschwebte, wie das ja überaus nahe lag. Die Folgerung aber, die Merkt daraus zieht, kann ich nicht anerkennen. Im Gegenteil: der ,plena fides per testes idoneos facta" (die sich in Gregors Bulle ubrigens auf die sonstigen Wunder, nicht auf die Stigmen bezieht), scheint mit voller Absicht die ,plenior fides reru m" im Schreiben Alexanders IV. entgegengestellt zu sein, der auf Zeugenaussagen beruhenden Glaubensgewißheit die durch den Augenschein der Dinge selbst gestützte Überzeugung! Und was Merkt aus Alexanders IV. Briefe an die Bischöfe von Kastilien von I259 hinzufügt, beruht nur auf einem Flüchtigkeitsfehler seinerseits; denn „,quorundam fide dignorum" hat Alexander nicht von den Stigmen, sondern von der Anzweifelung der Stigmen in Kastilien vernommen! Merkt behauptet weiter, der Ausdruck ,familiaris notitia" in Alexanders obengenannter Bulle von I255 könne nicht eine persönliche Bekanntschaft mit dem Heiligen, sondern nur eine genauere Kenntnis bezeichnen, wahrscheinlich durch das Kanonisationsverfahren vermittelt; denn Gregor IX. habe erst als Papst (I227), also nach Franzens Tode, seinen Neffen Rainald, den nachmaligen Alexander IV., in seine Dienste genommen, indem er ihn zum päpstlichen 
"camerarius" ernannte. Aber er geht auch da in der Irre. Aus dem Legatenregister des Kardinals Ugolino von Ostia ${ }^{1}$ ) hätte er sich leicht uberzeugen können, daß Rainald schon seit dem Jahre I22I als Kaplan in dessen persönlichem Dienste nachzuweisen ist.

Man mag es immerhin auffällig finden, daß der Kaplan Rainald die Stigmen geschaut haben sollte, wahrend das fur seinen Herrn und Oheim Kardinal Ugolino, den späteren Gregor IX., nicht nur unerweislich, sondern sogar unwahrscheinlich ist. ${ }^{2}$ ) Indessen, gerade wenn die Wundmale erst kurz vor Franzens Hinscheiden hervortraten, also nicht schon wahrend seines Aufenthaltes in Rieti vorhanden waren, ist eine Anwesenheit Rainalds allein bei dem Kranken doch keineswegs unmoglich, und so viel dürfte doch feststehen, daß Merkts Grunde gegen die Augenzeugenschaft Alexanders IV. nicht stichhaltig sind, und daß man uber dieselbe nicht kurzer Hand hinweggehen darf. Für die weiteren Ergebnisse ist die Frage ubrigens nur von untergeordneter Bedeutung. Denn über das Vorhandensein der Stigmen schon an dem Körper des lebenden Franziskus herrscht ja zurzeit Übereinstimmung unter den Forschern, so daß an einem Augenzeugen mehr oder weniger so sehr viel nicht gelegen ist.

Wie war das Aussehen der Wundmale? Goetz (S. 54) und Merkt (S. 54) stimmen mit mir darin durchaus überein, daß unser Urteil daruber auf den unmittelbar nach Franzens Tode geschriebenen Brief des Elias gegründet werden muß, da alle anderen Zeugnisse mindestens zwei Jahre später fallen und bereits legendarische Fortbildung verraten. Ich hatte in meiner Abhandlung gesagt, dieser Hauptgrundsatz einer methodischen Kritik, sich auf die zeitlich und ortlich allernächst stehende Quelle zu stützen, sei in unserem Falle fast noch rücksichtsloser als anderswo zur Geltung zu bringen. Damit ist Bihl nicht einverstanden; er bittet sich S. 537 , die Ermächtigung aus zur schüchternen Frage: weshalb nun gerade hier jener allbekannte Hauptgrundsatz fast noch rücksichtsloser als anderswo zu betonen sei".

1) Vgl. Fonti per la storia d'Italia Bd. 8, z. B. Urk. Nr. 18. 24. 38.43. 45. 7I. 75. I 10. Vgl. auch Tenckhoff, Papst Alexander IV. (1907) S. 2.

2) Hier verdienen Merkts Ausfuhrungen S. 7-14 Beachtung, wenn sie mir auch im einzelnen nicht immer zwingend erscheinen. 
Er hàtte die Antwort bereits meinem Aufsatz entnehmen konnen, in dem ich S. 390 betone: ,wir haben es durchweg nicht mit den ruhigen Beurteilungen medizinischer Sachverständiger oder überhaupt auch nur nüchterner Beobachter zu tun, sondern mit den durch religiose Vorstellungen voreingenommenen $\mathbf{1}$ ), durch leidenschaftliche Gemutserregungen getrübten, bald genug durch mundliche Weitererzählung und fortspinnende Phantasie umgestalteten Eindrücken von Mitgliedern einer Genossenschaft, die sich bei der immer zunehmenden legendarischen Ausschmückung gegenseitig in die Hände arbeiteten". Bihl (S. 537) ist freilich an dieser Stelle nicht achtlos vorbeigegangen, aber er hält die Bruder in der Sterbenacht ihres Stifters nicht fur so leidenschaftlich erregt, also in der Tat fur nuchterne Beobachter. Darin kann ich ihm allerdings nicht folgen!

Dies persönliche Moment ist ubrigens nicht der einzige Grund fur eine besonders rucksichtslose Anwendung jenes methodischen Prinzips auf den vorliegenden Fall; ein sachliches tritt hinzu. Wo es sich um enfache fest umrissene Tatsachen handelt, da mag man dem etwas späteren Berichterstatter wohl einmal das Wort lassen neben dem gleichzeitigen, namentlich, wenn der zeitlich spätere der raumlich nähere ist. Auch Urteile können sich oft erst im Laufe der Zeit abklären, wahrend der gleichzeitige Urteiler noch befangen ist. Aber bei jeglicher Art von Aufnahme eines Tatbestandes liegt die Sache erheblich anders! Hat Bihl keine Kenntnis von den neueren Forschungen zur Psychologie der Aussage? Dürfte in einem modernen Prozesse die erst nach mehr als zwei Jahren gegebene, auf Berichten anderer beruhende, literarisch geformte Schilderung eines Fernerstehenden gleich

1) Ein interessantes Beispiel dafur, wie sehr durch solche Voreingenommenheit die ruhige Beobachtung gestört ist, gibt uns z. B. Thomas von Eccleston ed. Little, Paris 1909, S. 95, wo nach dem Tode des ersten Minoritenministers von England Agnellus Pisanus folgendes erzählt wird: „Videbatur autem socio suo fratri W[altero] de Maddeley, quod funus (= Leiche) quoddam iacuit in choro, quod a cruce videbatur recenter depositum. Nam et quinque vulnera habuit in modum crucifixi Jesu Christi sanguinantia. Cum vero crederet, quod esset ipse dulcis Jesus Christus, appropinquans cominus vidit, quod erat frater Agnellus." Hier handelt es sich um reine Sinnestäuschung unter dem Einfluß religiöser Voreingenommenheit. 


$264 \quad$ Karl Hampe

oder gar höher bewertet werden als die unmittelbar nach der Tat gemachte, ungekunstelte Aussage eines sehr urteilsfähigen Nächstbeteiligten, gegen den der Verdacht absichtlicher Entstellung in keiner Weise vorliegt? Derartig aber ist das Verhältnis zwischen Thomas von Celano und Bruder Elias. Trotzdem meint Bihl: ,gerade hier, wo die Berichte so schnell aufeinander folgen, büßt jener Grundsatz sowohl von seiner Alleinberechtigung als auch, und das noch weit mehr, von seiner Forcierungsnotwendigkeit ein." Es hieße für die Leser dieser Zeitschrift offene Türen einrennen, wollte ich diese Auffassung noch weiter bekämpfen. Kein Zweifel, unser Urteil über die Beschaffenheit der Stigmen hängt schlechterdings ausschließlich ab von der richtigen Interpretation der betreffenden Stelle des Eliasbriefes.

Zunächst noch ein kurzes Wort über dessen Datierung. Ich habe in meiner Abhandlung (S. 387 Anm. I) bemerkt: „Die allgemein angenommene genauere Datierung desselben mit dem 4. Oktober I226 ist nicht zulässig. Denn wenn es am Schlusse heißt: 'Quarto Nonas Octobris die dominica prima hora noctis praecedentis pater et frater noster Franciscus migravit ad Christum', so ist doch klar, daß nicht die dem Schreiben, sondern die dem Sonntag voraufgehende Nacht gemeint ist. Für die Datierung des Briefes wird also damit nichts gewonnen." Bihl (S. 537 Anm. I) hat sich hier meiner Auffassung angeschlossen. Dagegen glaubt sie Merkt (S. 35 Anm.3) widerlegen zu können. Er behauptet: wenn die dem Sonntag voraufgehende Nacht gemeint wäre, müsste ,praecedere" mit dem Akkusativ konstruiert sein; es komme also nur die dem Schreiben voraufgehende Nacht in Betracht. Das ist eine willkürliche Annahme; der intransitive Gebrauch von praecedere ist ebensogut möglich. Die Entscheidung über die richtige Beziehung kann nur aus einer Beobachtung des damals in Italien üblichen Kalendergebrauches hergeleitet werden. Nun hat Bilfinger in seinem lehrreichen Buche „,Der bürgerliche Tag“ (I888) S. 276ff. ausgefuhrt, daß man in Italien zwar bei dem Übergang zu Schlaguhren mit gleicher Stundeneinteilung den Beginn des 24 Stunden umfassenden Tages auf den Sonnenuntergang des nach unserer Rechnung voraufgehenden Tages gesetzt habe, - wie er meint, weil die 
Altes und Neues uber die Stigmatisation des hl. Franz von Assisi ${ }_{265}$

Regulierung der Uhren sich da bequemer bewerkstelligen ließ. Jedenfalls aber werde die naheliegende Vermutung, die Italiener hatten auch früher schon den neuen Kalendertag mit der voraufgehenden Abenddammerung begonnen, durch die Quellen nicht bestätigt. Ich zweifle, ob er wirklich recht hat, wenn er einige Ausnahmen durch die Vermutung von Schreibfehlern beseitigen will, und ob nicht doch ein gewisses Schwanken des Gebrauches vorauszusetzen ist, - da könnten erst umfassendere Untersuchungen Gewißheit bringen. Jedenfalls war es nach Bilfinger die Regel, die Nacht noch zum voraufgehenden Kalendertage zu rechnen, wobei allerdings meist eine genauere Bezeichnung hinzugefugt wurde, wie etwa ,,in der folgenden Nacht", ,am Montag nachts den 6. September beim Herannahen des Dienstags" o. dgl. ${ }^{1}$ ) Wollten wir die obige Datierung nach dieser Regel bestimmen, so kämen wir zu dem Ergebnis, daß Franz nicht am Samstag den 3. Oktober I226 abends ${ }^{2}$ ), sondern erst am Sonntag den 4. Oktober zu derselben Zeit gestorben sei, und dann würde die ,,nox praecedens" in der Tat die Nacht sein, die dem Schreiben, nicht dem Sonntag voraufging; das Schreiben wäre dann freilich mit dem 5. Oktober zu datieren.

Ist diese Bestimmung nun richtig? Nein, wir haben es offenbar mit einer Ausnahmedatierung zu tun. Ich vermute, daß der Wunsch, den hl. Franz am Sonntag, dem Tage des Herrn, sterben zu lassen, hier zu der Einbeziehung der voraufgehenden Nacht in den folgenden Kàlendertag geführt hat, wozu, wie gesagt, wohl ein gewisses Schwanken im täglichen Gebrauch die Möglichkeit bot. Bonaventura (Opera ed. Quar. VIII, 548) ${ }^{3}$ ) bietet für Franzens Tod die gar nicht zu bezweifelnde Angabe: „,Transiit autem venerabilis pater ex huius mundi naufragio anno dominicae incarnationis millesimo ducentesimo vigesimo sexto, quarto nonas Octobris, die Sabbati in sero, sepultus in die do minico." Diese Angabe bildet eine offenbare Ausnahme von der von Bil-

1) Vgl. die Beispiele bei Bilfinger S. $278 \mathrm{ff}$.

5) Daß dies der richtige Tag sei, habe ich S. 387 Anm. I gerade gegenüber der meist beliebten falschen Datierung mit dem 4. Oktober betont. Vgl. jetzt auch Goetz S 57: „am Abend des 3. Oktober".

3) Danach Salimbene M. G. SS. XXXII, 35. 
finger angenommenen Regel, denn Samstag war eben der 3. Oktober; sie gibt aber auch eine sichere Handhabe fur die Interpretation unserer Stelle; auch da ist der Samstagabend gemeint, und jene voraufgehende Nacht ist ebenso zum folgenden Kalendertage gerechnet. „Praecedentis" ist also entgegen Merkts Ansicht doch auf den Sonntag zu beziehen, es entspricht dem sonst ub. lichen "la notte seguente" und ähnlichen Wendungen ${ }^{1}$ ); es ist fur das Verständnis schlechthin unentbehrlich, da sonst eben nicht der Samstag-, sondern der Sonntagabend als Todeszeit bezeichnet wurde.

Trotzdem bleibt naturlich die Moglichkeit bestehen, daß das Schreiben schon am Sonntag abgefaßt ist, und Merkt weiß dafür weiter eine Stelle des Brieftextes anzufuhren, nämlich die Worte: "Sed post mortem eius pulcherrimus aspectus est, miro candore rutilans, laetificans videntes"; denn ,aspectus" sei Substantiv, nicht etwa Verbum, und das Präsens beweise, daß Elias angesichts der Leiche Franzens, also noch am 4. Oktober schreibe. Das läßt sich schon eher hören; diese Auslegung der Stelle halte auch ich fur richtig. $\left.{ }^{2}\right)$ Allerdings erscheint es mir doch nicht ganz unmöglich, daß Elias auch nach der Einsargung der Leiche derartig im Präsens schreiben konnte, denn der begnadete Körper verlor damit doch nicht sogleich seine wunderbaren Eigenschaften, und Elias konnte am Ende auch am nächsten Tage noch aus der Stimmung des vorigen heraus schreiben. Mir wenigstens ist es nicht gerade wahrscheinlich, daß Elias schon am Beerdigungstage Muße zu einer so wohluberlegten und feinstilisierten Botschaft gefunden haben sollte, zumal der Brief an den Ordensminister in Frankreich ja nicht der einzige sein konnte, sondern Ähnliches überallhin gemeldet werden mußte.

Wie aber auch immer, ein ganz unmittelbares Zeugnis bleibt das Schreiben auf jeden Fall. Bihl (S. 539) bemüht sich nun, die darin enthaltene Beschreibung der Stigmen zu entwerten, indem er sie als knapp und mehr nebensächlich hinstellt; Elias

1) Vgl. Bilfinger a. a. O. S. $280 \mathrm{ff}$.

2) Auch die Anlehnung dieser und namentlich der kurz vorhergehenden Worte: "non erat in eo aspectus, sed despectus vultus eius" an Jesaj. 53, 2. 3 spricht dafür. 
habe die „ohnehin ja nicht unbekannte Tatsache der Wundmale" gewissermaßen nur nebenbei beruhrt. Wie vertragen sich damit jene Worte des Schreibens, welche die Schilderung der Wundmale einleiten: ,Et his dictis annuncio vobis gaudium magnum et miraculi novitatem. A saeculo non est auditum tale signum praeterquam in filio Dei, qui est Christus Deus"? Wie verträgt es sich mit Bihls eigenen Worten (S. 545): die große Anziehungskraft der Wundmale nach Franzens Tode sei „mehr als hinlänglich begründet eben in der Sorgfalt, mit der Franziskus die Nagelmale verborgen gehalten hatte, und in der unerhörten Neuheit des Wunders überhaupt"? Und wer immer Gelegenheit hatte, sich mit derartigen in die Legende hineinspielenden historischen Problemen zu beschäftigen, weiß zur Genige, daß breitere Ausmalung kein Vorzug, Knappheit keiñ Nachteil ist.

Nun aber zur Auslegung der wichtigen Stelle! Sie lautet bekanntlich: „Non diu ante mortem frater et pater noster apparuit crucifixus, quinque plagas, quae vere sunt stigmata Christi, portans in corpore suo. Nam manus eius et pedes quasi puncturas clavorum habuerunt ex utraque parte confixas, reservantes cicatrices et clavorum nigredinem ostendentes; latus vero eius lanceatum apparuit et saepe sanguinem evaporavit."

Man sollte denken, daß sich uber die richtige Interpretation der strittigen, gesperrt gedruckten Worte doch eine Übereinstimmung mußte erzielen lassen. Das ist indes bisher nicht der Fall. Ich selbst gab (S. 39I) folgende Übersetzung: „Denn seine Hände und Füße hatten gleichsam wie von Nägeln Löcher, die auf beiden Seiten durchgebohrt waren, Narben zurückbehaltend und die Schwärze von Nageln zeigend" und erklärte: , also offenbar vernarbte Löcher, in deren Risse sich der Schmutz gesetzt hat, und die sich nach dem Tode, als die Leiche gewaschen ist, um so dunkler von der weißen Haut abheben, dagegen keine nảgelförmigen Fleischauswüchse". Sowohl Bihl wie Merkt lehnen diese Auslegung $a b$, ohne doch untereinander übereinzustimmen. Denn Bihl (S. 538ff.) will in den Worten des Elias schon die schwarzen, fleischernen, an beiden Seiten mit Kopf und Spitze herausragenden Nagelgebilde erkennen, wie sie später Thomas 
von Celano schildert; Merkt (S. 53) spricht von schwärzlichen Punkten oder Flecken, die durch das in der Haut stehengebliebene Blut kleine Erhöhungen und durch das Eintrocknen, namentlich nach Eintritt der Totenstarre, gewisse narbige Linien zeigen. Goetz endlich (S. 55) nennt jene Male mit vorsichtigerer Unbestimmtheit „Narben mit dunklen Mittelpunkten“. Unter diesen Umständen muß ich meine Auslegung etwas näher begrunden.

Der Brief des Elias verrät einen feingebildeten Stilisten. Wie ich oben S. 266, Anm. 2 zu dem Worte ,,aspectus" auf eine Jesajasstelle hinwies, so sind auch sonst mehrfach biblische Erinnerungen frei verwertet. Wer immer über Christi Wundmale schrieb, mußte selbstverständlich der Geschichte vom ungläubigen Apostel Thomas (Johannes 20, 25) gedenken. Dort nun finden sich die Worte: „Nisi videro in manibus eius fixuram clavorum et mittam digitum meum in locum clavorum, _. _ non credam." Hier sind natürlich die leeren Nagelmale gemeint; Christus spricht: „Infer digitum tuum huc", und überhaupt wäre es ja völlig widersinnig, wenn der vom Kreuz Herabgenommene die dabei heraus. gezogenen Nägel selbst in Händen und Füßen trüge. Der Ausdruck „fixura clavorum" scheint singulär zu sein; da „figere" einschlagen, anheften u. dgl. heißt, so bedeutet es „das Mal, das die durchgeschlagenen Nagel hinterlassen haben". Hóchst auffällig erinnert an diesen Ausdruck im Eliasbrief die Wortverbindung ,punctura clavorum"; ich glaube, sie wäre ohne jenes Vorbild nicht entstanden. Sie ist wohl ebenso singulär, und sie bedeutet annähernd dasselbe, wenn auch mit einer abweichenden Nuance; da "pungere“ stechen heißt, so bedeutet die Wortverbindung in Analogie zu "fixura clavorum": „das Mal, das die durchgestochenen Nägel hinterlassen haben". Elias dürfte diese. abweichende Nüance nicht ohne Grund gewählt haben; die Male Franzens schienen ihm eben mehr von durchgestochenen als von rob mit dem Hammer durchgeschlagenen Nägeln herzurühren. Mir ist danach nicht verständlich, wie Merkt (S. 53) behaupten kann, meiner Erläuterung ,,stehe vom philologischen Gesichtspunkt im Wege, daß 'puncturae' eben nicht die Bedeutung 'Löcher' haben'. Ganz im Gegenteil: Merkt hätte erst Belege 
dafür beizubringen, daß ,punctura" in der dem Sinne des Stammwortes fremden Bedeutung ,Flecken" vorkomme, in der er es gebraucht!

Diese „Stiche" oder „Löcher" von Nageln sind nun ,, ex utraque parte confixae", d. h. sie gehen von der Außenseite zur Innenfläche und umgekehrt durch Fuße und Hände hindurch; sie sind "reservantes cicatrices", d. h. es sind keine offenen und blutenden Wundlöcher mehr, sondern schon ein wenig ältere, vernarbte Male. Sie sind endlich ,clavorum nigredinem ostendentes", d. h. sie zeigen die Schwärze von Nägeln, es ist, als ob solche schmiedeeisernen Nảgel auf die vernarbten Rảnder der Löcher abgefärbt hatten, - was in Wirklichkeit wohl am besten durch Schmutz, der sich in die Risse gesetzt hat, zu erklären ist.

Hier aber hat mich Bihl auf einem Mißverständnis ertappt. „Es lag im Zeitgeschmacke, statt des ${ }^{\complement}$ für uns anschaulicheren Adjektivums das feierlichere und abstrahierende Substantiv zu setzen", wie ,miraculi novitas" "ein neues Wunder" heißt, so „,nigredo clavorum" "schwarze Nägel". Diese selbst also oder vielmehr schwarze nägelartige Fleischgebilde sind der Kern der Male! Bihl traut mir, liebenswurdig wie er ist, hinreichende Belesenheit in der Literatur des Mittelalters zu, um leichthin selber ähnliche Beispiele zu häufen. Indem ich ihm gern zugestehe, daß ein derartiger Sprachgebrauch im mittelalterlichen Latein, namentlich bei Abstrakten, oftmals begegnet, bitte ich ihn, mich von der etwas unfruchtbaren Anlage einer entsprechenden Sammlung zu entbinden. Denn auch wenn ich mir einige Tausend Beispiele zusammenstellte, so wüßte ich ja damit noch immer nicht, ob dieser Sprachgebrauch auch auf unsere Stelle Anwendung findet. Von vornherein macht mich da schon die Erwähnung von Narben stutzig; denn wenn die Male in nägelartigen Auswuchsen bestanden, woher dann die Narben? Aber meine Auffassung ist vielleicht subjektiv. Sehen wir wie ein stilistisch feinfühliger Zeitgenosse die Worte aufgefaßt hat. Thomas von Celano in seiner Vita I (ed. E. d'Alençon) hatte bei seiner Schilderung der Wundmale c. 9 n. II2. II3, wie offenkundige Anlehnungen beweisen, den Brief des Elias vor sich. Um so mehr fällt auf, daß er mit nachdrücklichem Widerspruch die Stigmen dar 
stellt als "non clavorum quidem puncturas, sed ipsos clavos in eis impositos". Hier ist ganz deutlich, daß die "puncturae clavorum" des Elias die leeren Nagelmale sind, die also nicht schwarze Nägel in sich bergen. "Nigredo clavorum" ist also ebenso zu interpretieren, wie bei demselben Thomas von Celano "ferri retenta nigredine", "mit Zurückbehaltung der Schwärze des Eisens". Bihl wird freilich auch hier übersetzen müssen: „mit Zuruickbehaltung von schwarzem Eisen", so daß also in den Stigmen wirkliche Eisenstucke enthalten gewesen wären, - oder erscheint ihm das nicht doch auch allzu absurd?

Es bleibt also bei meiner früheren Auslegung, und ich halte es auch für methodisch bedenklich, für die Feststellung der Beschaffenheit von Franzens Stigmen auf die mehr oder weniger unzuverlässig beobachteten Analogieerscheinungen des 19. Jahrhunderts so großes Gewicht zu legen, wie Merkt (S. 52) tut. Findet Bihl (S. 538) es ferner auffallend, daß Elias überhaupt Nägel erwähnt, wenn derartige Gebilde nicht in Wirklichkeit auch zu sehen waren, so sollte ich meinen, daß die Vorstellung von Nágeln für den nicht fernliegen könne, der einmal von Christi Nägelmalen redet. Und wie es nun eine durchgehende Tendenz der Legende ist, Wundererscheinungen möglichst $\mathrm{zu}$ vergegenständlichen und zu vergrobern, so hat diese Tätigkeit der fortspinnenden Phantasie nach Franzens Tode schon sehr bald im Kreise seiner Jünger eingesetzt, so daß wir schon nach reichlich zwei Jahren ${ }^{\mathbf{1}}$ ) bei Thomas von Celano an die Stelle der Wundlocher fleischerne Nägelgebilde mit Köpfen und Spitzen treten sehen. Der Wunsch, die Wunderbarkeit der Erscheinung möglichst allen Zweifeln, wie sie ja bekanntermaßen bald genugsam auftauchten, zu entrücken, wird hier sicherlich mit als Hebel der Phantasie gewirkt haben, ohne daß ich indes diese Umwandlung als einen Ausfluß kühler und unehrlicher Berechnung auffassen möchte, wie Bihl S. 540 mit dem von mir nicht gebrauchten Adjektiv ,schlau" anzudeuten scheint.

1) Es ist doch wohl kein nennenswerter Unterschied, wenn ich die Vita I des Thomas von Celano als "bald nach 1228 " verfaßt bezeichne, während Bihl, der mir das S. 538 vorwirft, sie ,spätestens im Februar I229" vollendet sein läßt. Wir meinen natürlich beide dasselbe. 
Altes und Neues über die Stigmatisation des hl. Franz von Assisi

Daß Thomas von Celano, bei dem jede Spur eigner Augenzeugenschaft fehlt ${ }^{1}$ ), hier wie sonst in hohem Maße als phantasie. voller Künstler gearbeitet hat, geht auch aus den abweichenden Stigmenbeschreibungen seiner Sequenzen hervor, auf die Merkt S. 57 hingewiesen hat. Daß er sie da als offene Wunden hinstellt, kann freilich nicht so sehr befremden, da er ja den Vorgang der Stigmatisation selbst schildert, nicht das Aussehen der Wundmale an der Leiche. Wenn er weiter hinsichtlich der Außen- und Innenseite von Händen und Füßen ungenau ist und den inneren Stigmen ein rotlich-gelbes Aussehen (,flavi") zuschreibt, so mag man das mit der gebotenen dichterischen Kürze und dem Reimbedurfnis allenfalls erklären; immerhin zeigt das aber doch, daß ihm der künstlerische Gesichtspunkt höher steht als ein ängstliches Festhalten der nüchternen Wirklichkeit.

Daß endlich ,die Wundmale - damals etwas in der Kirche unerhörtes - dem Einflusse des auch bald um Franziskus von Assisi wuchernden Wunderwuchses sich ganz hatten entziehen können", ist auch nicht einmal Bihls Meinung (vgl. S. 540). So braucht hier auf diese Weiterentwicklung nicht näher eingegangen zu werden.

"Schwieriger gestaltet sich die Beantwortung der weiteren Frage: Wann sind die Wundmale zuerst aufgetreten?" mit diesen Worten hätte ich, ,etwas besorgt", so meint Bihl (S. 541), in meinem früheren Aufsatze zur ferneren Untersuchung ubergeleitet. Will man es Besorgnis nennen, daß ich damals wie heute mir klar bewußt war, an ein Problem heranzutreten, bei dem durch die Eigenart der Quellen eine glatte, auch den Widerstrebenden zwingende Losung von vornherein ausgeschlossen ist, so habe ich gegen den Ausdruck nichts einzuwenden. Überall, wo man sich, wie hier, zum Teil auf Wahrscheinlichkeitsschlusse stützen muß, wird dem Ergebnis ein Rest von Hypothetischem anhaften. Um so wertvoller ist es mir, daß Merkt, der sich in dieser Beziehung durchaus meiner Ansicht angeschlossen hat, gerade hier neue Belege bringt, die für mich sprechen. Sie sind aber vor-

"Zum "Tractatus de miraculis" verweise ich auf meine fruhere Äußerung, S. 389 meiner Abhandlung, und die Bemerkungen von Merkt, S. 25 . 
erst noch, ebenso wie Bihls Einwände, einer Prufung zu unterziehen.

Zunächst sträubt sich Bihl (S. 54I) wieder, unsre einzige wirklich gleichzeitige Quelle, den Eliasbrief, als "den einzigen sicheren Ausgangspunkt" unserer Untersuchung anzuerkennen. Es bedarf da keiner weiteren Worte. Die hier in Betracht kommende Stelle lautet: "Non diu ante mortem frater et pater noster apparuit crucifixus" usw. Ich habe (S. 394 Anm. I) gezeigt, daß der römische Druck des Briefes von Amoni, der im Anfang des Satzes die Lesart "nam" statt „non" bringt, nicht auf eine handschriftliche Vorlage zuruckgeht. Bihl selbst erkennt das an, indem er (S. 54I Anm. I) äußert: „K. Hampes Vermutung, daß Amoni wohl keine Handschriften vor sich hatte, wird wirklich bestatigt durch die von K. Hampe aufgezeigten Schlimmverbesserungen und ungeschickten Änderungen", ja er hält den Canonico Leopoldo Amoni noch für einen Grad einfältiger als ich. $\left.{ }^{1}\right)$ Damit aber begibt er sich nun doch des Rechtes, noch weiterhin von zwei Lesarten zu reden, von denen man keine mit Sicherheit als einzig richtige Form ansprechen könne, und wenn er das trotzdem tut, so verdient es keine Beachtung. Es ist daher auch kein Entgegenkommen, sondern Notwendigkeit, wenn er sich einmal auf meinen Standpunkt stellen will: "non" sei die richtige Wortform.

Mit Hase und neuerdings Merkt (S. 37) bin ich der Ansicht, ein unvoreingenommener Leser könne dies ",non diu", unmittelbar nach dem Tode eines fünfundvierzigjährigen Mannes geschrieben, nicht wohl als einen Zeitraum von über zwei Jahren auffassen. Bihl erkennt das nicht an; im Mittelalter habe man chronologische Formeln wie "kurz" und "lange" in unbestimmterem, vagerem Sinne gebraucht als heutzutage. Er führt als Beispiel dafür eine Stelle aus der Vita secunda des Thomas von Celano (c. 6 n. I I) an. „Nachdem Fr. Thomas von Celano dort

1) Vgl. S. 54r: „Wenn aber Hampe mutmaßt, in diesem Falle habe Amoni „einfach durch die Einsetzung des 'nam' den Folgerungen Hases aus dem 'non' den Boden" entziehen wollen, so tut eine derartige Unterstellung dem weiland guten Canonico Leopoldo Amoni doch wohl zuviel der Ehre an. Gewiß waren Hases Hypothesen vor den Nachstellungen des Kanonikus völlig gesichert." 
eine Erscheinung des Gekreuzigten erwähnt hat, die Franziskus wurde ganz im Anfange seiner Bekehrung, also I206 oder I207, ruft er unter anderem aus: 'Quis non stupet ista? Quis quandoque similia intellexit? .. . Ab ea igitur hora liquefacta est anima eius, ut dilectus ei locutus est. Patuit paulo post amor cordis per vulnera corporis!' usw. Hier umfaßt das unscheinbare 'paulo post' unserem Empfinden ganz entgegen eine Spanne Zeit von beiläufig I8 Jahren!" Bihl hätte dazu noch auf den Anfang des Kapitels verweisen können: „Mutatus perfecte iam corde, in brevi mutandus et corpore" usw. "Was ergibt sich nun daraus? Mussen wir die uns bisher gelaufigen Begriffe umlernen? Wird man künftig in einer mittelalterlichen Biographie „paulo post" unter Umstanden mit einem Zeitraum von I 8 Jahren erklären mussen? Und wo lagen eigentlich die Ursachen für solch verschiedenes Empfinden des mittelalterlichen Menschen? Ich glaube, "lang" und „kurz" waren damals ebenso relative Begriffe wie heute; es hing schon damals alles ab von dem Standpunkt und der Tendenz des Erzählers. Wer nach mehr als zwanzig Jahren rückschauend das Leben Franzens ohne jede Spur von chronologischem Interesse als eine Einheit betrachtete und das Bestreben hatte, Anfang und Ende seiner religiösen Wirksamkeit eng miteinander zu verknüpfen, das Ganze als ein Nachleiden der Passion Christi hinzustellen, das zuerst dem Herzen eingeprägt, dann auch am Leibe sichtbar wurde, der konnte wohl Ausdrucke anwenden, denen jede Allgemeingültigkeit für andere Verhältnisse abgeht. Sub specie aeternitatis kann kurz erscheinen, was sonst als lang bezeichnet wird. Es geht also wohl nicht an, aus einer solchen Stelle Schlüsse ziehen zu wollen für den Eliasbrief, in dem ein Nächststehender unmittelbar nach Franzens Hinscheiden äußert: ,nicht lange vor seinem Tode", zumal da hier die Tendenz wohl eher darauf gerichtet gewesen wäre, diese Zeit auch des außeren Nachleidens der Passion als eine möglichst lange hinzustellen ${ }^{1}$ ) und dadurch eine Tauschung uber das Wunder

1) In den beiden Analogiefällen, die Merkt S. 4 u. 5 aufzählt, wird dem. entsprechend die Zeit des Vorhandenseins der Stigmata mit dem Ausdruck "multis annis" möglichst weit gedehnt, obwohl man zum mindesten bei Dodon von Hascha, wie ausdruicklich betont wird, ganzlich auf Vermutungen angewiesen war, da ja ,hoc - ante diem mortis suae nullus scivit". 
in den Augen der auswärtigen Bruder von vornherein noch bestimmter auszuschließen. Das Argument behält also seine volle Kraft, wenn auch Bihl es fertig bringt, aus dem Eliasbrief sogar das Gegenteil herauszulesen: „das rasche Hinübergleiten uber die Wundmale deutet das Gegenteil an: dieselben waren hinlang: lich bekannt, also waren sie auch schon längere Zeit vorhanden. Zudem beruht ja die Annahme auf einer kritisch nicht gesicherten, sondern zweifelhaften Lesart". Ich brauche dazu nach meinen obigen Bemerkungen nichts hinzuzufugen.

Mit der Angabe des Eliasbriefes stimmt vortrefflich uberein diejenige des schon 1236 gestorbenen Roger von Wendover, Benediktiners in St. Albans ${ }^{\mathbf{1}}$ ), zu dem zwar, wahrscheinlich von Rompilgern ihm zugetragen, entstellte und übertreibende Berichte über Franzens Wundmale drangen, aber mit ihnen auch der zeitliche Vermerk, sie seien "quintadecima die ante exitum suum" hervorgetreten, eine Nachricht, die doch nicht ohne weiteres von der Hand gewiesen werden kann, zumal sie an dem Eliasbrief eine Stutze findet. Bihl (S. 544 Anm. I) sucht diese Angabe auf eigenartige Weise zu entkräften: zufällig habe der Chronist gerade den Monat von Franzens Alvernoaufenthalt, den September, erfahren, aber nicht das Jahr I224; er habe nun irrig das Todesjahr angenommen und, da Franz am 3. Oktober I226 starb, mit seinen Worten: „am I5. Tage vor seinem Tode" in der Tat einen Tag im September bezeichnet (freilich weder den richtigen Tag der Legende, das Fest der Kreuzeserhohung, den 14. September, noch das richtige Jahr!). Wie unwahrscheinlich ist das! Wie viel wahrscheinlicher, daß ihm wirklich eine wahre Kunde neben manchen falschen Nachrichten zugeflossen ist!

Wichtig ist es nun, daß Merkt hier zwei weitere Quellenbelege anzuführen weiß, welche die Angaben des Eliasbriefes und Rogers von Wendover zu erhärten geeignet sind. Ich sage zwei, denn den dritten Gewährsmann, Ubertino von Casale, muß ich ablehnen, nicht weil seine hier herangezogene Schrift erst dem Anfang des I4. Jahrhunderts angehört - denn trotzdem könnte

1) Nicht Westminster, wie Bihl S. 544 sagt, der übrigens auch die minoritenfeindliche Tendenz des Fortsetzers Matthaeus Paris auf Roger von Wendover überträgt. 
sie ja eine historische Wahrheit festgehalten haben -, sondern weil sich Merkt (S. 40ff.) in der Deutung der betreffenden Stelle offenkundig versehen hat. Diese lautet: ,Et certe testimonium habuit (Franciscus) a summo pontifice Christo, quod regula a Christo data, quam bullavit bulla mirabili, volens institutionem (lies: 'institutorem') ipsius in sancte regule testimonium paucis post eius confectionem diebus passionis suae stigmatibus insignire". Indem Merkt jene „regula" fur das von den Spiritualen hochverehrte Testament Franzens halt und dieses in seine letzte Zeit setzt, glaubt er einen neuen Beleg fur das späte Auftreten der Wundmale zu gewinnen. Indessen scheidet Ubertino in seiner ganzen Schrift vollkommen deutlich die Regel von I223 und das Testament ${ }^{\mathbf{1}}$ ), und hätte Merkt an obiger Stelle noch etwas weiter gelesen, nämlich die Worte: ,Et postquam predicta habuit a Christo testimonia, expressit Dei et suam intencionem de observancia regule, sicut dictum est supra", so hätte er wohl selbst eingesehen, daß erst hier das Testament gemeint ist, jene 'regula' also nur die Regel von 1223 sein kann. Der aus weiter Ferne zurückschauende Ubertino schiebt eben die Vorgảnge der letzten Jahre des Franziskus halb unabsichtlich, halb absichtlich eng aneinander; chronologisch ist die Stelle nicht $\mathrm{zu}$ verwerten.

Brauchbar ist dagegen der Bericht der bis 1243 gefuhrten Reimchronik des Philipp Mousket († I244), den Merkt (S. 39) nur nicht in so schlechter Textwiedergabe, sondern nach Toblers Auszügen M. G. SS. XXVI hätte anführen sollen. Hier erfolgt die Stigmatisation auf Franzens Gebet zu Gott ,a sa mort", „bei seinem Sterben“, und im Anschluß daran wird von seinem Tod und den Wundererscheinungen danach berichtet. Man wird Mousket für diese Dinge gewiß keine besonders hohe Autorität zuschreiben wollen; immerhin steht er ihnen zeitlich noch ziem. lich nahe.

Um so höher dürfte die ebenfalls von Merkt (S. 38) herangezogene Äußerung Jakobs von Vitry, des Bischofs von Akkon und Kardinalbischofs von Tuskulum, zu bewerten sein.

1) Vgl. z. B. in der Ausgabe von Ehrle (Archiv f. Literatur- u Kirchengesch. d. Mittelalters Bd. 3) S. 52.53. 
Ich will hier nicht im einzelnen ausführen, welch außerordentlich lebhaftes Interesse dieser dem hl. Franz und seinem Orden von den Anfängen an zugewendet hat, wie wertvolle Nachrichten wir ihm daruber verdanken, die dadurch nur an Bedeutung gewinnen, da $B$ er der Bewegung zwar wohlwollend, aber doch nicht völlig ohne Kritik gegenüberstand. Ich kann hier auf die $\mathrm{Zu}$ sammenstellung in dem neuen Buche von Ph. Funk, Jakob von Vitry (1909) S. I69ff. verweisen. ${ }^{1}$ ) Jakob von Vitry weilte etwa vom Herbst I 225 bis zum Sommer I 226 in Italien, um sich dann nach dem Niederrhein zu wenden. Es ist undenkbar, daß er damals nicht genauere Kunde uber das Ergehen des Franziskus erhalten haben sollte. Auch von 1229 ab hatte er an der Kurie in Perugia, Rieti, Spoleto usw. beste Gelegenheit, etwaige Lücken seiner Kenntnis auszufüllen. Ebendieser sagt nun in einer an die Minderbrüder gerichteten Predigt von Franz: „In morte eius in pedibus, manibus et latere vestigia vulnerum Christi apparuerunt." Leider läßt sich die Entstehung dieser Predigt nicht genauer datieren, als durch die Jahre I226-40.2) Es ware natürlich wertvoll, wenn man feststellen könnte, daß sie etwa noch ein früheres Zeugnis bildete, als des Thomas von Celano Vita I (I229); aber im übrigen kommt bei der vorauszusetzenden vertrauten Kenntnis Jakobs für diese rein tatsächliche Nachricht nicht allzuviel darauf an, ob ein etwas früheres oder späteres Jahr anzunehmen ist. Ebenso liegt nicht viel daran, ob man Merkts Ansicht, die Predigt sei vor Mitgliedern des Franziskanerordens wirklich gehalten, nach den Bemerkungen von Funk S. I76ff. dahin abwandelt, daß es sich vielleicht nur um eine literarische Musterpredigt handelt, denn auch in diesem Falle war sie ja an die Franziskaner gerichtet und mußte ihre Aufmerksamkeit auf sich lenken. Ich möchte auch kein Gewicht darauf legen, daß, wie Merkt meint, das Verbum ,apparuerunt" die Tätigkeit des Zutagetretens der Wundmale ausdrücke, was sich wohl nur bei einem Lebenden denken lasse, so daß also ,in morte" wiederzugeben sei mit ,,als Franz im Sterben lag", - wenn ich diese Übersetzung auch für

1) Vgl. in dieser Zeitschr. oben S. $217 \mathrm{ff}$.

2) Eine genaue Prüfung der teilweise noch ungedruckten Sermones vulgares könnte vielleicht $z \mathfrak{u}$ einem bestimmteren Ergebnis fuhren. 
richtig halte. ${ }^{\mathbf{1}}$ ) Sicher ist jedenfalls, daß Jakob von Vitry die Stigmatisation mit dem Zeitpunkt des Todes in Verbindung bringt, was sich mit der Version von ihrem Hervortreten auf dem Monte Alverno uber zwei Jahre vor Franzens Tode nicht wohl vereinigen läßt.

Es ist nun doch höchst beachtenswert, daß die drei zeitgenössischen Gewährsmänner, deren Zeugnisse geeignet sind, die Angabe des Eliasbriefes zu erhärten, Roger von Wendover, Philipp Mousket, Jakob von Vitry, alle außerhalb des Franziskanerkreises stehen und daher von der dort inzwischen eingeburgerten Tradition unabhängig sind. Um so sicherer durfen wir an der Angabe des Elias und ihrer unvoreingenommenen Deutung festhalten und sind nicht gezwungen, jenes ,, non diu ante mortem" gewaltsam zu einem Zeitraum von uber zwei Jahren auszurecken. Merkt hat (S. 43) uberdies gezeigt, daß die Stimmung der letzten Tage des Heiligen den Vorgang psychologisch zum mindesten ebensogut motiviert wie der Aufenthalt in der Bergeinsamkeit des Monte Alverno.

Freilich, ästhetisch eindrucksvoller ist die Schilderung des Thomas von Celano sicherlich, und es muß immer wieder betont und auch für die Biographie des Heiligen wohl noch in höherem Maße fruchtbar gemacht werden, da $B$ in ihm der literarische Künstler den Historiker doch stark uberwiegt. Die ,Alverno. tradition" ist von ihm begründet und hat infolge der Bestätigung und Sanktion der Vita I durch Papst Gregor IX. ${ }^{2}$ ) im Orden kanonische Geltung erlangt. Sie ist daher künftig wohl noch im einzelnen weiter ausgeschmückt, aber im wesentlichen durchaus festgehalten. Alle franziskanischen Äußerungen seit I 229 stimmen darin überein; durch Ausschaltung des von Merkt als abweichender Gewährsmann genannten Ubertino von Casale wird die Einstimmigkeit nur noch vollkommener. Es ist klar, daß diese Äußerungen sich nicht gegenseitig zu stützen vermögen, da sie ja alle

1) Man könnte zur Stïtze dafür hinweisen auf das analoge ,apparuerunt" bei Matthaeus Paris: "Itaque quintadecima die ante exitum suum de corpore apparuerunt vulnera" usw.

9) Vgl. in der Ausgabe von E. d'Alençon S. 152: "Gregorius nonus.... legendam hanc recepit, confirmavit et censuit fore tenendam." 
von der gleichen Quelle abhảngig und überdies in ihrer Unbefangenheit durch die päpstliche Sanktion beschrankt sind. Es steht also Thomas von Celano mit seiner franziskanischen Gefolgschaft gegenuber dem Eliasbrief mit sảmtlichen außerfranziskanischen Zeugnissen. Läßt es sich wahrscheinlich machen, wie Thomas zu seiner poetisch verklärten und den religiosen Bedurfnissen entsprechenden, aber von der historischen Wahrheit absichtslos abweichenden Darstellung gekommen sei, so wird man nicht mehr Bedenken tragen, den entgegenstehenden Äußerungen den Vorzug zu geben.

Eine solche Erklarung habe ich in meinem fruheren Aufsatze versucht: die Wundmale erst in Franzens letzter Zeit von einigen seiner Genossen zufällig beobachtet, aber von dem demütigen Heiligen möglichst verborgen; nach seinem Tode Unklarheit über Zeit und Art ihrer Entstehung; Bedürfnis, sich fur die literarische Ausgestaltung der Legende nicht mit einem non liquet begnügen zu müssen; Vermutung eines Zusammenhangs mit der Seraphsvision auf dem Monte Alverno, deren Inhalt Franz niemandem ganz enthullt hatte, und mit dem Zeitpunkte des Festes der Kreuzeserhöhung 1224; Verdichtung dieser Vermutung zur Überzeugung; legendarisch-anekdotische Versuche, das langere Verborgenbleiben der Stigmen einigermaßen erklärlich zu machen. Ich will meine Argumente im einzelnen um so weniger wiederholen, als Merkt (S. 44ff.) sich mir hier yöllig angeschlossen und die Hypothese noch einmal in neuer Form begrundet hat.

Der Hauptfehler von Bihls Ausfuhrungen zu diesem Punkte (S. $545 \mathrm{ff}$.) ist, daß er von der Vermengung von Seraphsvision und Stigmatisation sich auch nicht einmal bedingungsweise freimachen kann und die Zeugnisse für jene von niemandem bestrittene Vision ohne weiteres fur die Alvernotradition der Stigma. tisation verwendet (so namentlich S. 545). Er bezweifelt ferner, daß Franz sich niemals selbst uber die Entstehung der Wundmale geäußert habe; aber warum dann das demütige Streben nach ihrer Geheimhaltung, das dem Charakter des Heiligen so ganz entspricht? Warum vor allem später nicht der geringste Hinweis auf solche jeden $Z_{\text {weifel niederschlagenden }}$ Äußerungen und auf die Jünger, die sie vernommen, während man wiederholt 
so besonderes Gewicht darauf legte, Augenzeugen der Male zu nennen ${ }^{\mathbf{1}}$ ) Weiter fragt Bihl, weshalb gerade das Gesicht aus dem sechsten Kapitel des Jesajas Anregung zu der Form von Franzens Seraphsvision geboten haben soll, warum nicht etwa das erste Kapitel Ezechiels oder das vierte Hauptstuck der Offenbarung Johannis? Ich antworte: weil allein bei Jesajas Seraphim vorkommen, weil deren Schilderung mit den sechs Flügeln und ihrer Anordnung, das Herabschweben eines Seraphs und die Enthullungen, die er dem erschütterten Visionär macht, mir die formalen Voraussetzungen fur Franzens Gesicht zu sein scheinen, wahrend jene andern beiden von Bihl angefuhrten Visionen mit ihren Tierbildern und ihrem auch sonst ganz abweichenden Inhalt doch nicht ernstlich in Betracht zu ziehen sind.

Indem ich andere wenig belangreiche Bemerkungen Bihls, wie die Anzweiflung, ob die "familiares" und "collaterales fratres" und ,devotissimi secutores", denen Franz lange Zeit die Stigmen glucklich verbarg, auch wirklich seine allerintimsten Genossen gewesen seien, übergehe, komme ich noch mit wenigen Worten auf das Zeugnis des Bruders Leo zu sprechen, der ja als einer der Gefährten des Heiligen in der Bergeinsamkeit des Alverno besondere Berucksichtigung verdient. Es liegt von ihm bekanntlich vor eine kurze beglaubigende, vermutlich ziemlich spate ${ }^{2}$ ) Bemerkung zu dem die "Laudes Dei" und „Benedictio Leonis" enthaltenden Autograph des Franziskus. Darin heißt es zum Alvernoaufenthalt im September 1224 von Franz: „post visionem

1) Man vgl. auch die Stelle bei Thomas von Eccleston ed. Little S. 93: „Frater Johannes de Parma minister generalis in pleno capitulo generali Januae (zwischen I 245 u. 1253 , vgl. Little S XXIV u. S. 53. 93. I26) praecepit fratri Bonicio, qui fuerat socius sancti Francisci, ut diceret fratribus de stigmatibus suis veritatem, quia multi de hoc per orbem dubitabant. Et respondit cum lacrymis: 'Isti oculi peccatores ea viderunt et istae manus peccatrices contrectaverunt ea'." Warum nirgends ein Zurïckgreifen auf die authentische Äußerung des Franziskus, wenn es eine gab?

2) Leo starb erst r 270. Der Ausdruck „, beatus Franciscus" weist jedenfalls auf die Zeit nach der Kanonisation. Die ganze Art, einen solchen Zettel zu beglaubigen, spricht wohl eher fur spàtere Jahre, wo diejenigen selten wurden, welche Franzens Handschrift kannten. Merkt S. 46 führt auch stilvergleichende Momente furr eine späte, durch die Biographien, auch Bonaventuras, beeinflußte Niederschrift an. 


$280 \quad$ Karl Hampe

et allocutionem Seraphym et impressionem stigmatum Christi in corpore suo fecit has laudes". Wer kunftighin an der kirchlich sanktionierten oder sonst ihm liebgewordenen Alvernotradition unbeirrt festhalten mochte, wird gut tun, sich zäh an dies Blatt zu klammern: ein Genosse Franzens aus jenen Septembertagen bestätigt, daß er dort die Wundmale erhalten; damit erledigen sich alle sonstigen Zweifel!

Ich freue mich, daß Merkt an diesem rein mechanischen Verfahren keinen Geschmack gefunden, sondern meine abweichende Anschauung übernommen und zum Teil mit neuen Belegen gestützt hat. Bruder Leo stand als Franziskaner unter dem Einfluß der päpstlich sanktionierten Legende; persönlich wußte er nichts Genaueres uber das erste Hervortreten der Stigmen, er scheint sie erst an der Leiche Franzens gesehen zu haben. Denn wie sollen wir es uns sonst erklären, daß er dem wissensdurstigen Salimbene nicht ein Wort über die Alvernoszene und das damalige wunderbare Hervortreten der Wundmale zu sagen wußte, sondern nur von den Malen am Toten sprach? ${ }^{\mathbf{1}}$ ) Was er selbst über die Alvernovision aussagen konnte, ist uns durch die Aufzeichnung des Bruders Garynus de Sedenefeld ${ }^{2}$ ) in der Chronik des Thomas (von Eccleston) erhalten: Der Seraph erscheint dem Heiligen deutlicher, greifbarer (",satis evidentius"), als in der Vita (des Thomas von Celano) beschrieben ist. Franz erschrickt stark, als er ihn von weitem erblickt und erzahlt nachher dem Bruder Rufinus, daß jener ihn hart mitgenommen habe (,,quod eum dure tractavit"). Der Engel steht auf einem Stein, den Franz nachher zu waschen und salben befiehlt; er macht Enthüllungen, die der Heilige nur zum Teil dem Rufinus wiedererzählt hat.

Bei der starken Abweichung dieses Berichtes von der Version des Thomas von Celano darf man wohl mit Sicherheit behaupten, daß dieser vor der Abfassung seiner Vita I die Aussagen von Nächstbeteiligten, wie Leo und Rufinus, uber die Alvernoszene

1) Ich verweise auf die uberzeugenden Ausfuhrungen von Merkt S. 45.

2) Das betreffende Gespräch zwischen Bruder Leo und dem Ordensminister von England Peter von Tewkesbury dürfte, nach dessen Amtstitel zu schließen, nach 1254 und vor dem Abschluß der Chronik 1258/59 stattgefunden haben; vgl. die Ausgabe von Little S. 127 und S. XXI. 
Altes und Neues uber die Stigmatisation des hl. Franz von Assisi 28 I

nicht eingeholt hat, denn wie hätte er sonst diese wertvollen Angaben ganz unter den Tisch fallen lassen kónnen? Für die Kritik seiner Darstellung ist das sehr zu beachten! Ich will hier nicht noch einmal im einzelnen die Widerspriche zwischen Leos und Thomas' Berichten hervorheben: zwischen dem einfachen Engel und dem Mischwesen von Seraph und Crucifixus, zwischen dem Schweben in der Luft und dem Stehen auf dem Stein, zwischen den Enthüllungen und der Stigmatisation. Bihls Ausfuhrungen zu diesem Punkte zeigen, daß man sie mit viel gutem Willen zu einer einheitlichen Darstellung zusammenzwingen kann, aber der Eindruck des unbefangenen Lesers wird schwerlich dahin gehen, und mit den Worten: , apparitio Seraphyn facta fuit sancto Francisco-satis evidentius, quam scribatur (so ed.Litile) in vita sua" scheint mir keineswegs gesagt zu sein, daß im folgenden nur Lucken im Berichte des Thomas von Celano ausgefullt werden sollen. Ebenso wird man in der Äußerung des Franziskus über den Engel "quod eum dure tractavit" einen bestimmten Hinweis auf die Stigmatisation schwerlich erblicken konnen. Ein ähnliches Moment - ich weiß nicht, ob etwa veranlaßt durch körperliches Leiden unter dem ekstatischen Zustand - dürfte bei Visionären öfter anzutreffen sein. Schon die Bibel liefert da manche Beispiele. Des Jesajas Lippen berührt der herabschwebende Seraph mit einer glühenden Kohle, Jakob ringt mit dem Engel und wird von ihm an der Hufte verletzt (Gen. 32, 25), Johannes stürzt vor dem Anblick des Menschensohnes wie tot nieder (Apoc. I, I7) usw. Auch den Ausdruck „,visitationibus pulsatus insolitis", den Thomas von Celano in seiner Vita II c. 6 bei andererGelegenheit von dem Heiligen braucht, darf man hier vielleicht erwähnen. Genug, was Franz mit dem „dure tractare" bezeichnen wollte, ob Worte oder Handlungen des von ihm im Geiste geschauten Seraphs gemeint sind, ]äßt sich schlechterdings nicht ausmachen. Andrerseits mag Bruder Leo darin später eıne Andeutung erblickt haben, die es ihm erleichterte, die Vorgänge der Stigmatisation und Vision im Anschluß an Thomas von Celano zusammenzuschieben. Und nur weil er das tat, konnte seine Erzählung bei Thomas (von Eccleston) in den Zusammenhang gebracht werden, in dem sie dort erscheint. Indem sie nämlich 
an den oben S. 279 Anm. I zitierten Vorgang auf dem Generalkapitel in Genua anknüpft, soll sie einen weiteren Beleg fur die Tatsächlichkeit der Stıgmatisation bringen. Das gleiche Interesse hat offenbar dies ganze Gespräch Leos mit Peter von Tewkesbury erst veranlaßt, das hier berichtet wird. Und trotzdem fehlt jene Aussage Leos, die allein von durchschlagender Kraft gewesen wäre, und die so nahe gelegen hàtte: „Ich selbst habe die Wundmale sogleich nach jener Seraphsvision bei dem Heiligen erblickt!" Dieser Mangel scheint mir an der ganzen Erzählung doch das Bemerkenswerteste zu sein.

Interessant ist es nun, worauf wiederum Merkt (S. $58 \mathrm{ff}$.) hinweist, daß wir eine sehr alte Darstellung der Alvernoszene ohne jede Andeutung der Stigmatisation besitzen, also gleichsam eine Illustration zu Leos Bericht bei Thomas (von Eccleston). Es ist ein Fresko im Baptisterium zu Parma, das einen Seraph neben dem hl. Franz stehend darstellt und uns nach Thodes 1 ) Urteil ,einen lebhafteren Begriff von dem Heiligen gibt, als die meisten andern Portrats". Eine Abbildung') habe ich mir leider nicht verschaffen können. $\mathrm{Da}$ das Gemàlde, wie Merkt offen läßt, vielleicht schon vor der Kanonisation entstanden sei, wird durch den Heiligenschein des Franziskus ausgeschlossen; doch verdient beachtet zu werden, daß es sich hier nicht, wie sonst meist, um eine Franziskanerkirche handelt, der Kunstler also der Legende wohl unbefangener gegenuberstand. Nach einer Notiz bei Venturi, Storia dell' arte italiana III (1904) S. 4I5 wäre der Terminus ad quem für das Fresco das Jahr 1283; es gehore also etwa in die Mitte des I3. Jahrhunderts. Venturi bezieht sich auf Pietro Tosca, der eine Monographie uber die Bilder des Baptisteriums fur den sechsten Band der Gallerie nazionali italiane vorbereite. Diese Monographie ist trotz der frühen Ankundigung meines Wissens noch nicht erschienen. Merkt sieht in diesem Parmeser Fresco ,die glảnzendste bildliche Bestatigung" meiner Meinung, daß die ganze Alvernoszene in einer Engelsvision bestand und mit den erst kurz vor dem Tode des Heiligen

1) Franz v. Assisi, 2. Aufl., S. 75; vgl. S. 147.

2) Thode ebenda zitiert Flaminio di Parma, Memorie istoriche delle chiese d. fr. min. della provincia di Bologna, I760, II, S. I60. 
Altes und Neues über die Stigmatisation des hl. Franz von Assisi 283

hervorgetretenen Wundmalen urspringlich nichts zu tun gehabt hat.

Erst nachdem die auf die Feststellung des Tatbestandes gerichtete kritische Untersuchung zu einem, wenn nicht völlig gesicherten, so doch mindestens wahrscheinlichen Ergebnis gefuhrt hat, läßt sich die Frage nach einer Erklärung des Vorganges aufwerfen, denn ,,auch Rätsel und Wunder lassen uns nur eine Hoffnung auf Lösung und Erklärung, wenn vor allem ihr Tatbestand festgestellt ist. "1) Daß fur mich hier nur der Weg einer natürlichen Erkläung in Betracht kommt, brauche ich kaum zu bemerken; vollig unfruchtbar müBte daher in dieser Hinsicht jede Auseinandersetzung mit Bihl bleiben, da er neben der empirisch-historischen Erkenntnis auch theologischen oder philosophischen Wissenschaftsmethoden das Wort geben will, die außerordentliche, ja übernaturliche Wunderkrafte mit in Rechnung stellen.

Ich habe in meinem früheren Aufsatz unter den verschiedenen Erklärungsmöglichkeiten, die sich bieten, keine bestimmte Entscheidung getroffen und bin auch noch heute der Meinung, daß sie dem Historiker nicht eigentlich zusteht. Immerhin kann er natürlich versuchen, sich mit Hilfe des Neurologen ${ }^{2}$ ) ein Urteil zu bilden, und da glaube ich, daß gerade nach dem auch hier manches Neue bringenden Buchlein von Merkt die Wagschale sich mehr und mehr zugunsten der Selbstbeibringung senkt, einer in heiliger und demutiger Nacheiferung des Leidens Christi erfolgten, bewußt oder unbewußt ausgeubten asketischen Handlung. Auch Goetz (S. 54 ff.) scheint, ohne die andere Erklärungsmöglichkeit durch Autosuggestion ganz auszuschließen, mehr dieser Ansicht zuzuneigen. Merkt dagegen, der S. 62 ff. recht gute Bemerkungen $z u$ der Frage macht, zieht aus seinem eigenen Material meines Erachtens nicht scharf genug die Folgerungen. Wenn er schließlich der Annahme der Autosuggestion den Vorzug gibt, so wirkt darauf einmal die, wie ich oben gezeigt zu haben

1) Vgl. den anregenden Aufsatz von W. Hellpach, Historische Hysterie, Neue deutsche Rundschau 1906, S. I030.

2) Meinem Freunde Prof. S. Schönborn in Heidelberg bin ich fuir mehrfache belehrende Auskunft zu Dank verpfichtet. 
hoffe, irrige Anschauung über die Beschaffenheit der Wundmale als dunkler Flecken; denn vernarbte Wundlöcher, wie sie mir im Eliasbriefe deutlich gekennzeichnet zu sein scheinen, setzen einer Erklärung durch Autosuggestion sicherlich die erheblichsten Schwierigkeiten entgegen, während sie wohl für jeden Mediziner mit großer Wahrscheinlichkeit auf Selbstbeibringung hinweisen. Ferner aber dürfte Merkt vielleicht zu starkes Gewicht auf die späteren Stigmatisationsfälle legen, von denen ja einzelne wirklich - bei verschiedenem Befunde - durch Autosuggestion zu erklären sein mögen, die aber doch eigentlich alle erst in ihrem Tatbestand auf das genaueste gepruft werden müßten, ehe man sie hier verwenden könnte.

Wichtiger erscheinen mir die zeitgenössischen Analogiefälle, auf die Merkt selbst hingewiesen hat. Sie lehren uns, daß die asketische Neigung zur Nachahmung der Wundmale Christi in jenen Tagen verbreiteter war, als man bisher angenommen hat. Franz von Assisi ist auch nicht mehr als der erste historisch beglaubigte Stigmatisierte $z u$ betrachten. Über seinen freilich gründlich verschiedenen Vorläufer, der vom Oxforder Konzil des Jahres 1222 als Religionsschänder abgeurteilt wurde, kann ich einige weitere Belege bringen. Der Fall ist immerhin interessant genug, um dabei einen Augenblick zu verweilen. Der von Merkt herangezogene, übrigens schlecht abgedruckte Text des Matthaeus Paris (Chron. Mai. ed. Luard III, 7I) lautet: „Hoc etiam anno (I222) comprehensus fuit quidam paucis diebus ante concilium celebratum Cantuariae a magistro S[tephano] Cantuariensi archiepiscopo, habens in corpore et membris, scilicet in latere, manibus et pedibus, quinque vulnera crucifixionis; et in dicto concilio simul cum eo [quidam] utriusque sexus, scilicet Ermofroditus, eiusdem erroris, quo prior fuit obcaecatus, cum suo complice praesentatus. Super quo convicti et publice confessi, iudicio ecclesiae puniti fuerunt" usw.

Diesem Bericht stellt Merkt eine aus einem vatikanischen Manuskript geschöpfte Nachricht in den Annalen des Bzovius (a. 1222 n. XX) gegenüber: ,In synodo Cantuariensi seu mavis Oxoniensi hoc anno in Anglia celebrato pseudochristus quidam, qui se Christum venisseque, ut errores, qui in clero et populo 
Altes und Neues uber die Stigmatisation des hl. Franz von Assisi 285

grassarentur, emendaret, audebat asserere; et signa quaedam quasi Christi crucifixi, manibus, pedibus laterique impressa, ad maiorem populi circumventionem ostendebat, ut vanus et perfidus nebulo in crucem, quam meruit, cum hermaphrodito quodam assecla sublatus est" usw. Merkts Ansicht, diese Nachricht sei durchaus unabhängig von Matthaeus Paris, kann ich nicht teilen. Nicht nur der Irrtum betreffs Canterbury, der mit einem ziemlich neuzeitlich anmutenden ,seu mavis Oxoniensi" unsicher verbessert ist, sondern auch die weitgehende Übereinstimmung des Wortlautes weist eben auf Matthaeus Paris als Vorlage hin. $\mathrm{Ob}$ uberhaupt noch eine weitere Quelle hineingearbeitet ist, läßt sich ohne nähere Kenntnis des betreffenden vatikanischen Manuskripts kaum mit Sicherheit sagen. Die Kreuzesstrafe ist, wie gleich $z u$ ersehen sein wird, zweifellos irrig; die reformerische Tendenz, die den Verurteilten hier zugeschrieben wird, könnte immerhin einer moderneren Vermutung entstammen, wenn da auch eine selbständige ältere Quelle nicht ausgeschlossen ist. Jedenfalls darf man diese zweifelhafte Annalenstelle in einer Überlieferung aus dem Beginn des 17. Jahrhunderts nicht so hoch bewerten, wie Merkt (S. 3) es tut.

Zuverlässiger als selbst Matthaeus Paris sind die beiden folgenden, ganz gleichzeitigen Berichte:

- Annales de Waverleia (Annales monastici ed. Luard II, 296): „Dominus Stephanus Cantuariae archiepiscopus celebravit concilium suum primum apud Oxoniam XV. kal. Maii. In hoc concilio quidam diaconus apostata, qui duxerat quandam Judaeam, degradatus est et postea combustus. $\left.{ }^{1}\right)$ Quidam etiam rusticus, qui se crucifigebat, immuratus est perpetuo."

Annales de Dunstaplia (ebenda III, 76):

„Eodem anno post Pascha Stephanus Cantuariensis archiepiscopus, apud Oxoniam concilium celebravit mense Aprili; ubi

1) Über diesen hier nicht weiter in Betracht kommenden Fall, uber den auch Matthaeus Paris und Bzovius im Anschluß an die oben aus ihnen angefuhrten Stellen kurz berichten, scheint F. W. Maitland, Roman canon law in the church of England (1898) VI: „The deacon and the Jewess" ausfuhrlicher gehandelt zu haben. Das Buch ist mir nicht zur Hand; ich weiß daher auch nicht, ob etwa der Stigmatisationsfall darin gestreift wird. 
recitatum est et observari mandatum concilium Lateranense; in quo condemnatus est ad incendium, post degradationem suam, diaconus quidam, qui pro amore cuiusdam mulieris Judaeae fuerat circumcisus; et per balivos regis ibidem praesentes extra burgum igne crematus est. Alius diaconus propter furtum ibidem degradatus est. Insuper et mulier quaedam, quae se fecit Sanctam Mariam et iuvenis quidam, qui se fecerat Christum et perforaverat sibimet manus et latus et pedes, immurati sunt apud Bannebirre. ${ }^{1}$ ) Et capitula multa sunt ibi de novo statuta.

Auch bei dem zwei Generationen jungeren sogen. Thomas Wykes geht das folgende offenbar auf eine gute alte Nachricht des Klosters Osney zurück (ebenda IV, 63):

"In eodem concilio praesentatus est quidam diaconus" usw. (Näheres uber ihn und die Jüdin.) Dann: ,Oblatus est in e ode m concilio rusticus quidam laicus, qui in tantam devenit insaniam, ut in ignominiam crucifixi se faceret crucifigi, asserens se filium Dei et redemptorem mundi, quique iudicio concilii immuratus totum vitae suae residuum reclusus duro pane et aqua refectus in car. cere terminavit."

Was ergibt sich aus diesen weiteren Quellenbelegen? Der Ver. urteilte war kein Geistlicher oder auch nur gebildeter Laie, sondern ein junger Bauer; eine ernstlichere Reformtendenz, wie sie die Stelle bei Bzovius vermuten ließe, ist daher wenig wahrscheinlich. Er ist nicht etwa zum Tode verurteilt worden, sondern zur ewigen Einmauerung bei Banbury mit notdürftigem Unterhalt von Wasser und Brot und hat da anscheinend noch länger gelebt. Sein Schicksal teilte eine Frauensperson, nach der Bezeichnung „,mulier" älter als er, der ,,iuvenis", aber wohl kaum seine Mutter, da das vermutlich angedeutet wäre. Die Analogie des „se fecit Sanctam Mariam" zu dem ,se fecerat Christum" scheint mir darauf zu deuten, daß auch hier ein Fall von Selbstverstümmelung vorliegt, und die charakteristische Eigenschaft der Maria, die bei einer Nachahmung irgendwie äußerlich anzudeuten war, ist

1) Banbury n. Oxford. 
Altes und Neues uber die Stigmatisation des hl. Franz von Assisi 287

ihre Jungfrảulichkeit. Ich vermute daher, daß es sich um eine, vollständig oder auch nur teilweise ausgeführte Amputation der Bruste gehandelt hat ${ }^{\mathbf{1}}$ ), wodurch der Körper ein mädchenhaftes, ja unweibliches Aussehen erhielt. Und hier liegt dann auch wohl der Anlaß fur die merkwürdige Bezeichnung des Matthaeus Paris: „,[quidam] utriusque sexus, scilicet Ermofroditus". Denn an der Identitat der beiden Persönlichkeiten ist gar nicht zu zweifeln, da auch dieser angebliche, gewiß nicht ganz wörtlich zu nehmende Hermaphrodit von demselben religiosen Wahn befangen sein soll wie der Stigmatisierte.

"Religióser Wahn", das dürfte nun auch die nächstliegende Erklärung für den Vorgang sein. ${ }^{2}$ ) Plumpe Betrüger, die sich derartig bittre Leiden zufügen ohne die mindeste Aussicht, in der gewählten Rolle einen Ersatz durch weltliche Freuden zu finden, wollen mir wenigstens nicht glaubhaft erscheinen. Diese Angehörigen des niederen Volkes sind offenbar in der allgemeinen religiosen Erregung der Zeit von krankhaften Wahnvorstellungen ergriffen worden und haben im Zustande der Hysterie jene Handlungen an sich begangen. Man kennt ja auch genugsam die ansteckende Wirkung solcher Hysterie auf ahnlich gerichtete Naturen, um aus der Verbindung dieser beiden Menschen nicht etwa auf ein kuhl überlegtes Komplott schließen zu müssen.

Je weniger hier vermutlich von irgendwelcher individuellen Bedeutung die Rede sein kann, um so mehr interessiert der Fall als unmittelbares Produkt der Zeitstimmung, und so gewaltig ohne Frage der persönliche Abstand vom hl. Franz ist, eine ge-

3) Auf die zeitgenössische, schon I213 gestorbene Begine Maria von Oignies, die sich, um die Leiden des Gekreuzigten (,stigmata domini nostri Jesu Christi") an ihrem Leibe zu empfinden, in ekstatischem Zustand heimlich nicht unbetràchtliche Fleischstucke aus ihrem Körper herausschnitt und in der Erde verbarg, habe ich schon in dieser Zeitschrift oben S. 221 hingewiesen. Jene Pseudomaria mag zu ihr etwa in demselben Verhältnis stehen wie der Oxforder Pseudochristus zum hl. Franz.

2) Von einem ähnlichen Pseudochristus und einer Pseudomaria berichtet schon Gregor von Tours, Hist Franc. X, 25; da ist das Pathologische ganz offenkundig, und man erfährt sogar die Ursache: Stiche eines Insektenschwarms erzeugen zweijahrigen Irrsinn, der dann von jener religiösen Wahnvorstellung abgelöst wird. 
wisse Verwandtschaft in den asketisch-hysterischen Motiven ist kaum zu bestreiten. Beachtenswert ist ferner, wie nahe hier Religionsschändung und Heiligkeit im Urteil der Kirche bei einander liegen; wir verstehen danach um so eher, daß man in Rom mit $Z_{w}$ eifeln und Widerspruch gegen das Stigmenwunder rechnen mußte, und daß man sich scheute, die Kanonisation des Franziskus damit zu begrunden.

Der Oxforder Fall von 1222 ist der einzige, dem man ohne jeden Zweifel die Prioritat vor der Stigmatisation des hl. Franz zuzuweisen hat. Unsicherer liegen die beiden anderen von Merkt (S. 4ff.) herangezogenen Falle; da sie erst eine Zeitlang nach Franzens Tode aufgezeichnet sind, so ist eine Beeinflussung durch die Franzlegende zeitlich wenigstens nicht völlig ausgeschlossen.

Namentlich für die von einem anonymen, wahrscheinlich pramonstratensischen Verfasser geschriebene Biographie des

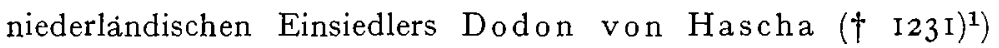
ist diese Möglichkeit in Betracht zu ziehen. An ihm fand man nach seinem Tode „vulnera aperta in manibus et pedibus et dextro latere suo, ad modum quinque vulnerum Domini, quae forte ad compatiendum crucifixo multis annis portavit, ut vere dicere posset cum Paulo: ego stigmata domini mei Jesu Christi in corpore meo porto. Hoc autem ante diem mortis suae nullus scivit, nisi solus Deus, qui omnia noscit." Da der Verfasser ihn wegen seiner asketischen Selbstpeinigungen fast als Märtyrer betrachtet, so denkt er bei den Stigmen wohl nur an Selbstzufügung, wie auch aus den Worten ,,ad compatiendum crucifixo" hervorgeht. Die Zeitdauer (,multis annis") ist nur Vermutung (,forte"), da ja niemand vor Dodons Tode etwas davon wußte.

Besser beglaubigt und von selbständigerem Werte ist die asketische Handlungsweise des I234 verstorbenen Marquis Robert von Montferrand in der Auvergne. Der Dominikaner Stephan von Bourbon ( $\dagger$ c. I26I) hat darüber berichtet in seinem um $\left.1260^{2}\right)$ geschriebenen „Tractatus de diversis materiis prae-

3) Vgl. Acta Sanctorum Mart. III. S 85 Iff.

3) Das geht aus der Stelle bei Lecoy de la Marche S. 138. I39 hervor. Zur Zeit von Stephans Tod vgl. ebenda S. IX. 
Altes und Neues uber die Stigmatisation des hl. Franz von Assisi

dicabilibus", aus denen Lecoy de la Marche unter dem Titel "Anecdotes historiques" (1877) Auszuge veroffentlicht hat. Ein eigenartiger Kauz muß jener alte Marquis gewesen sein! Vierzig Jahre lang hat er mit großen Muhen und Kosten alle sektiererischen Schriften, deren er habhaft werden konnte, gesammelt und eifrig studiert, so daß er daruber in den Verdacht geriet, selbst ein Ketzer zu sein. Aber er wußte diese Meinung schlagend $\mathrm{zu}$ widerlegen: $\mathrm{je}$ eifriger das Studium, desto größer sei sein Abscheu geworden, und dem habe er den denkbar stäksten Ausdruck verliehen, indem er den Kasten mit jenen Buchern zu seinem Fußschemel gemacht habe, wenn er im heimlichen Gemach seiner Wohnung seine Notdurft verrichtete! ${ }^{1}$ ) Von ihm nun heißt es: "Qui multis annis ante mortem suam in memoriam passionis eius et fidei stigmata domini Jesu in corpore suo portaverat. Cum alis penitenciis, quas faciebat in memoriam passionis Domini, cum quibusdam clavis carnem suam singulis sextis feriis usque ad sanguints effusionem configebat." Fuhrt der Ausdruck, ,viele Jahre vor seinem Tode" von 1234 ruckwärts zu einem Termin, der mit der Stigmatisation Franzens als einigermaßen gleichzeitig angesehen werden darf, so spricht auch die ganz abwerchende Darstellung für Unabhangigkeit von dessen Legende. Von enem Wunder ist hier ebensowenig wie bei Dodon von Hascha die Rede; vielmehr wird die asketische Selbstbeibringung ausdrücklich zugegeben und uberdies noch eine periodisch an allen Freitagen wiederholte, wie sie Merkt (S. 66) ausschließlich den durch Autosuggestion zu erklàrenden Faillen vorbehält.

Also eine Anzahl von zeitgenössischen Beispielen für Stigmatisationen läßt sich doch aufzeigen! Bei allen ${ }^{2}$ ) sind, soweit wir urteilen konnen, die Motive ahnlich wie bei Franziskus,

1) Vgl. ebenda S. $276:-\ldots$ „Et in signum huius vilipensionis, quam habebam ad alias sectas a fide, feci fieri scrineum ligneum, quod feci poni sub pedibus meis, quando sedebam in sede camere mee private, quasi non possem ipsas sectas magis vilipendere, nisi pedibus meis subessent, quando sedeo vile nature officium expleturus."

2) Der Oxforder Fall steht unter den andern wohl einigermaßen gesondert da, durfte aber im letzten Grunde, wie oben ausgefuhrt, doch auf ahnlicher Basis ruhen.

Archiv für Kulturgeschichte. VIII. 3 . 
eine Mischung von Kontemplation und Askese, uberall wohl mit einem starken Einschlag von Hysterie. Bei allen ist an der Selbstzufuigung nicht zu zweifeln. Auch bei Franz war die Neigung zu asketischer Selbstverwundung stark ausgepragt; mit Recht betont Merkt (S. 63) die Stelle aus der Vita II des Thomas von Celano (c. 92), wo es von Franz heißt: „Corpus enim suum, utique innocens, flagellis et penuriis subigebat, multiplicans ei vulnera sine causa." Die Selbstzufugung aber war auch das Ergebnis, zu dem meine obige Untersuchung mit einiger Wahrscheinlichkeit gelangte, und so dürften vor dieser Lösung des Rätsels die andern etwaigen Erklärungsmöglıchkeiten doch mehr und mehr zuruicktreten!

\section{Nachtrag.}

Im Archivum Franciscanum historicum ann. III, fasc. 5 veröffentlicht soeben P. M. Bihl einen neuen Aufsatz: „De stigmatibus S. Francisci Assisiensis", der mir erst nach Erledigung der Korrektur meiner Abhandlung zuging und daher nicht mehr berücksichtigt werden konnte. Abgesehen von dem Hinweis darauf, daß schon ein Abdruck des Eliasbriefes von Melchiorri (I856) die ältere Druckvorlage durch die Änderung des "non diu" in "nam diu" verdorben hat, und Amoni dadurch von einem schändlichen Verdacht entlastet wird, unterscheidet sich die neue Darlegung, soweit dabei ich in Betracht komme, von der früheren übrigens nur durch den zweifelhaften Vorzug eines sehr persönlichen Lateins. Diese in jüngerer Zeit unter altphilologischer Mitwirkung besonders nach der Seite der Invektiven ausgebaute Sprache ist, so möchte ich zugunsten Bihls annehmen, die Hauptursache dafür, daß in seinen Angriffen gegen Merkt die frühere Höflichkeit des Tones arg gelitten hat. Auf Einzelheiten einzugehen, fehlt mir hier der Raum. Einige Hinweise verdienen Beachtung; aber in allen wesentlichen Punkten finde ich nicht den mindesten Anlaß, meine obigen Ausführungen zu ändern. 